\title{
Local velocity scaling in an impeller discharge flow in T400 vessel agitated by tooth impeller in a fully turbulent region
}

\author{
Radek Šulc ${ }^{1,{ }^{*}}$, Pavel Ditl ${ }^{1}$, Ivan Fořt ${ }^{1}$, Darina Jašíkova ${ }^{2}$, Michal Kotek ${ }^{2}$, Václav Kopecký ${ }^{2}$, and Bohuš Kysela ${ }^{3}$ \\ ${ }^{1}$ Czech Technical University in Prague, Faculty of Mechanical Engineering, Department of Process Engineering, Technická 4 , \\ 16607 Prague, Czech Republic \\ ${ }^{2}$ Technical University of Liberec, Institute for Nanomaterials, Advanced Technology and Innovation, Studentská 1402/2, 46117 \\ Liberec, Czech Republic \\ ${ }^{3}$ Czech Academy of Sciences, Institute of Hydrodynamics v.v.i, Pod Pat'ankou 30/5, 16612 Prague, Czech Republic
}

\begin{abstract}
Hydrodynamics and flow field were measured in an agitated vessel using 2-D Time Resolved Particle Image Velocimetry (2-D TR PIV). The experiments were carried out in a fully baffled cylindrical flat bottom vessel $400 \mathrm{~mm}$ in inner diameter agitated by a tooth impeller $133 \mathrm{~mm}$ in diameter. The velocity fields were measured in the impeller discharge flow for impeller rotation speeds from $300 \mathrm{rpm}$ to $700 \mathrm{rpm}$ and three liquids of different viscosities (i.e. (i) distilled water, ii) a $28 \%$ vol. aqueous solution of glycol, and iii) a $43 \%$ vol. aqueous solution of glycol), corresponding to the impeller Reynolds number in the range $68000<\operatorname{Re}<221000$. This $\mathrm{Re}$ range secures the fully-developed turbulent flow of agitated liquid. In accordance with the theory of mixing, the dimensionless mean and fluctuation velocities in the measured directions were found to be constant and independent of the impeller Reynolds number. On the basis of the test results the spatial distributions of dimensionless velocities were calculated. The radial turbulence intensity was found to be in the majority in the range from 0.3 to 0.9 , which corresponds to the high level of this quantity.
\end{abstract}

\section{Introduction}

It is important to know the flow and the flow pattern in an agitated vessel in order to determine many impeller and turbulence characteristics, e.g. impeller pumping capacity, intensity of turbulence, turbulent kinetic energy, convective velocity, and the turbulent energy dissipation rate. The information and data that are obtained can also be used for CFD verification.

In PIV studies, the spatial distributions of various properties are often presented. However, the inspection analysis shows that the validity of the spatial distribution of any dimensionless property for arbitrary process conditions in geometrically similar agitated vessels requires independence of a given dimensionless property from the impeller Reynolds number. The spatial distribution that is obtained is in general valid only when this independence is both theoretically predicted and experimentally verified. Unfortunately, in many studies the results are presented only for one impeller speed and, in addition, the experiments are often carried out under the transient flow regime.

Kysela et al. [1] investigated the flow discharging from a Ruhston turbine, Šulc et al. [2] presented the local velocity profiles in the zone in upward flow to the impeller for three impeller rotation speeds in a vessel $300 \mathrm{~mm}$ in the inner diameter filled by a water and agitated by a Rushton turbine, as well. In our previous work [3] the scaling of the velocity field in the zone in upward flow to the impeller for three liquids of different viscosities in a vessel $400 \mathrm{~mm}$ in the inner diameter agitated by a Rushton turbine were presented.

Agitation of two immiscible liquids or solid-liquid suspension is a frequent operation in chemical and metallurgical industries [4]. In this case the tooth impeller has been used usually for dispersion process [5].

The aim of this work is to study scaling of the velocity field in the impeller discharge flow in a vessel $400 \mathrm{~mm}$ in inner diameter mechanically agitated by a tooth impeller (CVS 691038.1) in a fully turbulent region for three liquids of different viscosities. The independency of dimensionless spatial velocity distribution on the impeller Reynolds number was tested statistically. The hydrodynamics and the flow field were measured in an agitated vessel using Time Resolved Particle Image Velocimetry (TR PIV).

\section{Theoretical background}

\subsection{Inspection analysis of flow in an agitated vessel}

The flow of a Newtonian fluid in an agitated vessel has been described by the Navier - Stokes equation: 
$\rho \cdot\left(\frac{\partial \vec{U}}{\partial t}+\vec{U} \bullet \nabla \vec{U}\right)=-\nabla p+\mu \cdot \nabla^{2} \vec{U}+\rho \cdot \vec{g}$

This equation can be rewritten into dimensionless form, as follows (e.g. [6]):

$$
\left(\frac{\partial \vec{U}^{*}}{\partial t^{*}}+\vec{U}^{*} \cdot \nabla^{*} \vec{U}^{*}\right)=-\nabla^{*} p^{*}+\frac{1}{\operatorname{Re}} \cdot \nabla^{* 2} \vec{U}^{*}+\frac{1}{F r} \cdot \vec{n}^{*}
$$

where the dimensionless properties are defined as follows:

- dimensionless instantaneous velocity:

$$
\vec{U}^{*}=\frac{\vec{U}}{N \cdot D}
$$

- dimensionless instantaneous pressure:

$$
p^{*}=\frac{p}{\rho \cdot N^{2} \cdot D^{2}}
$$

- dimensionless space gradient: $\nabla^{*}=\frac{\nabla}{D}$,

- impeller Reynolds number $\operatorname{Re}=\frac{N \cdot D^{2}}{v}$,

- impeller Froude number: $\quad F r=\frac{N^{2} \cdot D}{g}$,

and where $\vec{n}$ is a unity vector.

Similarly, the equation of continuity for stationary flow of a non-compressible fluid is given

$$
\nabla \bullet \vec{U}=0
$$

and can be rewritten into the dimensionless form as follows:

$$
\nabla^{*} \bullet \vec{U}^{*}=0
$$

The following relations can be obtained for the dimensionless velocity components and the dimensionless pressure, respectively, by inspection analysis of Eqs. (2) and (5), as follows:

$$
\begin{aligned}
\vec{U}^{*} & =f_{1}\left(\vec{x}^{*}, t^{*}, \operatorname{Re}, F r\right), \\
p^{*} & =f_{2}\left(\vec{x}^{*}, t^{*}, \operatorname{Re}, F r\right),
\end{aligned}
$$

where $\vec{x}^{*}$ is a dimensionless location vector.

For stationary flow with a periodic character the velocity time dependence can be eliminated by substituting the velocity and pressure by time-averaged properties. For highly turbulent flow in an agitated baffled vessel, the viscous and gravitational forces can be neglected and finally the time-averaged dimensionless velocity components and the pressure are independent of the impeller Reynolds and the Froude numbers, and depend on location, only:

$$
\begin{aligned}
& \bar{U}_{i}^{*}=f_{1}\left(\vec{x}^{*}\right), \\
& p^{*}=f_{2}\left(\vec{x}^{*}\right) .
\end{aligned}
$$

Reynolds decomposition of instantaneous velocity components has been applied for the velocity profiles studied in this work.

\subsection{Mean and fluctuation velocity}

Using PIV, the instantaneous velocity data set $U_{i}\left(t_{j}\right)$ in the $\mathrm{i}^{\text {th }}$ direction for $j=1,2, \ldots N_{R}$ at observation times $t_{j}$ with equidistant time step $\Delta t_{S}$ (i.e. $\Delta t_{S}=t_{j+1}-t_{j}$ ) was obtained in a given location. Assuming the ergodic hypothesis the time-averaged mean velocity $\bar{U}_{i}$ was determined as the average value of velocity data set $U_{i}$ $\left(t_{j}\right)$ :

$$
\bar{U}_{i}=\frac{1}{N_{R}} \cdot \sum_{j} U\left(t_{j}\right) \text { for } j=1,2, \ldots, N_{R},
$$

where $\bar{U}_{i}$ is mean velocity in the $\mathrm{i}^{\text {th }}$ direction, $U_{i}\left(t_{j}\right)$ is instantaneous velocity in the $i^{\text {th }}$ direction at the observation time $t_{j}$, and $N_{R}$ is the number of data items in the velocity data set.

Consequently, the fluctuation velocity in the $\mathrm{i}^{\text {th }}$ direction $u_{i}\left(t_{j}\right)$ at observation time $t_{j}$ is obtained by decomposition of the instantaneous velocity:

$$
u_{i}\left(t_{j}\right)=U_{i}\left(t_{j}\right)-\bar{U}_{i} \text { for } j=1,2, \ldots, N_{R},
$$

where $u_{i}\left(t_{j}\right)$ is the fluctuation velocity in the $\mathrm{i}^{\text {th }}$ direction at observation time $\mathrm{t}_{\mathrm{i}}, \bar{U}_{i}$ is mean velocity in the $\mathrm{i}^{\text {th }}$ direction, $U_{i}\left(t_{i}\right)$ is instantaneous velocity in the $i^{\text {th }}$ direction at the observation time $t_{i}$.

The root mean squared fluctuation velocity is determined as follows:

$$
\bar{u}_{i}=\left(\frac{1}{N_{R}} \cdot \sum_{i} u_{i}^{2}\left(t_{j}\right)\right)^{1 / 2} \text { for } j=1,2, \ldots, \mathrm{N}_{\mathrm{R}},
$$

where $\bar{u}_{i}$ is the root mean squared fluctuation velocity, and $u\left(t_{i}\right)$ is the fluctuation velocity at observation time $t_{i}$.

\section{Experimental}

The hydrodynamics and the flow field were investigated in an agitated vessel using Time Resolved Particle Image Velocimetry (TR PIV). The experiments were carried out in a fully baffled cylindrical flat bottom vessel 400 $\mathrm{mm}$ in the inner diameter. The tank was agitated by a tooth impeller $133 \mathrm{~mm}$ in diameter, i.e. the dimensionless impeller diameter $D / T$ was $1 / 3$. 
Table 1. Operational parameters.

\begin{tabular}{|c|c|c|c|c|c|}
\hline Run \# & liquid & $\begin{array}{c}\mathrm{N} \\
(\mathrm{rpm})\end{array}$ & $\begin{array}{c}v \\
\left(\mathrm{~m}^{2} / \mathrm{s}\right)\end{array}$ & $\begin{array}{c}\text { Re } \\
(-)\end{array}$ & $\begin{array}{c}\text { Record time } \mathrm{T}_{\mathrm{R}} \\
(\mathrm{s})\end{array}$ \\
\hline w-N300 & water & 300 & $9.35 \times 10^{-7}$ & 94641 & 8 \\
w-N500 & water & 500 & $9.35 \times 10^{-7}$ & 157735 & 8 \\
w-N700 & water & 700 & $9.35 \times 10^{-7}$ & 220829 & 8 \\
g28-N700 & 28\% glycol & 700 & $2 \times 10^{-6}$ & 103186 & 8 \\
g43-N700 & $43 \%$ glycol & 700 & $3 \times 10^{-6}$ & 68791 & 8 \\
\hline
\end{tabular}

The dimensionless impeller clearance $C / D$ taken from the lower impeller edge was 0.75 . The tank was filled with degassed liquid, and the liquid height was $400 \mathrm{~mm}$, i.e. the dimensionless liquid height $H / T$ was 1 . The dimensionless baffle width $B / T$ was $1 / 10$. To prevent air suction the vessel was covered by a lid.

Three liquids of different viscosities were used as the agitated liquid: i) distilled water $\left(v=9.35 \times 10^{-7} \mathrm{~m}^{2} / \mathrm{s}\right)$, ii) a $28 \%$ vol. aqueous solution of glycol $\left(v=2 \times 10^{-6} \mathrm{~m}^{2} / \mathrm{s}\right)$, and iii) a $43 \%$ vol. aqueous solution of glycol $\left(v=3 \times 10^{-}\right.$ $\left.{ }^{6} \mathrm{~m}^{2} / \mathrm{s}\right)$. The velocity fields were detected at an impeller rotation speed in the range from $300 \mathrm{rpm}$ to $700 \mathrm{rpm}$, which covers the impeller Reynolds number range from 68000 to 221000 . This Re range secures the fullydeveloped turbulent flow regime. The operational conditions are summarized in Table 1.

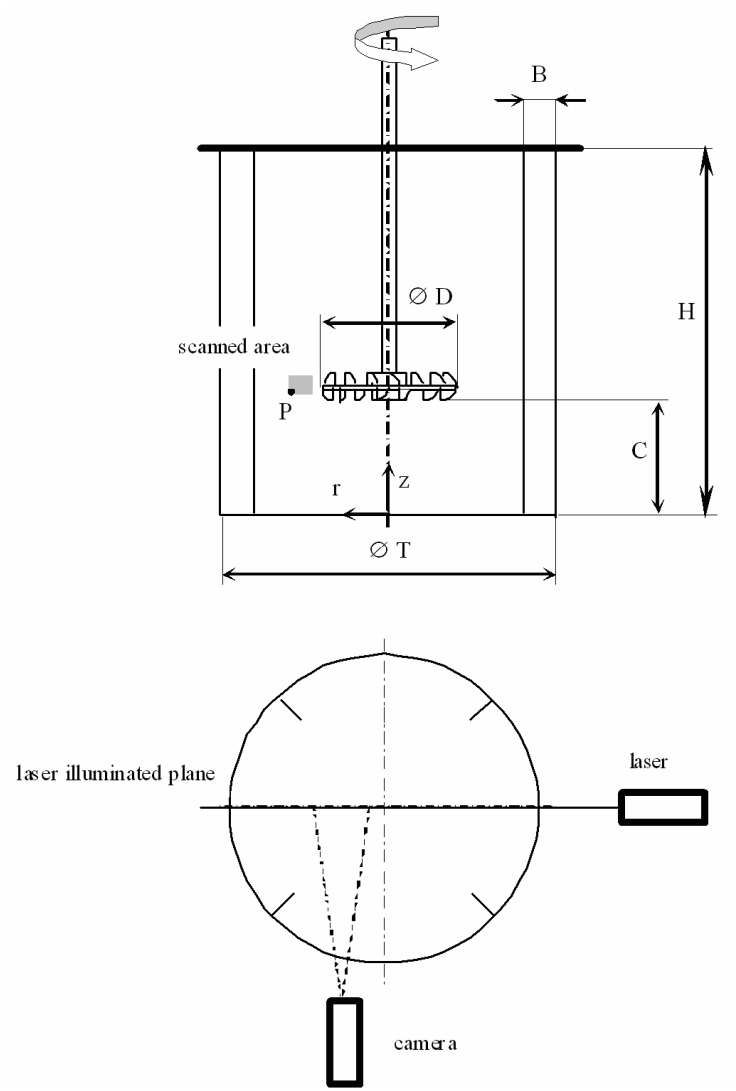

Fig. 1. Scheme of the experimental apparatus and the investigated area.

The time-resolved LITRON LDY 302 2D-PIV system (Dantec Dynamics (Denmark)) consists of a Neodyme-YLF laser (light wave length $532 \mathrm{~nm}$, impulse energy 2x15 mJ), a SpeedSence 611 high speed PIVregime camera (working on frequency $1 \mathrm{kHz}$ with resolution 1280 x 800 pixels) with a Nikon Macro 200 optical lens system equipped with an optical filter of wave length $570 \mathrm{~nm}$. Rhodamine B fluorescent particles $11.95 \pm 0.25 \mu \mathrm{m}$ in mean diameter were used as seeding particles. The fluorescent particles lit by $532 \mathrm{~nm}$ light emit $570 \mathrm{~nm}$ light. In this way, non-seeding particles such as impurities and bubbles are separated, and are not recorded. The operating frame rate was $1 \mathrm{kHz}(1000$ vector fields per second), i.e. the sampling time $\Delta t_{s}$ was 1 ms. The measured vertical plane was located in the center of the vessel and in the middle of the baffles. The plane was illuminated by a laser sheet. The investigated area was $25.6 \times 16 \mathrm{~mm}$, and the PIV spatial resolution $\Delta$ $=0.64 \mathrm{~mm}$ was maintained the same during the experiment. The length of the record time was selected so that relevant results were obtained [7].

The position of left bottom apex $\mathrm{P}\left[r_{P} ; z_{P}\right]$ was $[106$; 105], i.e. dimensionless radius $2 r / T=0.53$ and dimensionless height $z / T=0.2625$, i.e. the left bottom edge was located $8 \mathrm{~mm}$ below the impeller paddle axis and $106 \mathrm{~mm}$ from the impeller axis. The scheme of the experimental apparatus and the investigated area is depicted in Fig. 1. The camera was positioned orthogonally to the laser sheet. The investigated area corresponds to region $\mathrm{O}$ according to the classification given by Fořt et al. [8].

\section{Experimental data evaluation}

According to the inspection analysis, the dimensionless velocities normalized by the product of impeller speed $N$ and impeller diameter $D$ should be independent of the impeller Reynolds number.

The effect of impeller Reynolds number on dimensionless velocities was tested by hypothesis testing ([9]). The statistical method of hypothesis testing can estimate whether the differences between the predicted parameter values (e.g. according to some proposed theory) and then the parameter values evaluated from the measured data are negligible. In this case, we assumed dependence of the tested parameter on the impeller Reynolds number, described by the simple power law correlation parameter $=B \cdot R^{\beta}$, and the difference between predicted exponent $\beta_{\text {pred }}$ and evaluated exponent $\beta_{\text {calc }}$ was tested. The hypothesis test characteristics are given as $t=\left(\beta_{\text {calc }}-\beta_{\text {pred }}\right) / s_{\beta}$ where $s_{\beta}$ is the standard error of parameter $\beta_{\text {calc }}$. 
Table 2. Dimensionless velocities - effect of the impeller Reynolds number

\begin{tabular}{|c|c|c|}
\hline & \multicolumn{2}{|c|}{$\begin{array}{c}\text { Hypothesis: parameter }=\mathrm{B} .(\mathrm{Re})^{0} \\
\text { percentage } / \mathrm{t} \text {-characteristics }|\mathrm{t}|\end{array}$} \\
\hline Parameter & acceptable & not acceptable \\
\hline $\bar{U}_{r} /(N D)(-)$ & $86.9 \% / 1.37$ & $13.1 \% / 5.6$ \\
\hline $\bar{U}_{a x} /(N D)(-)$ & $90.9 \% / 1.0$ & $9.1 \% / 5.41$ \\
\hline $\bar{u}_{r} /(N D)(-)$ & $86.3 \% / 1.36$ & $13.7 \% / 4.94$ \\
\hline $\bar{u}_{a x} /(N D)$ & $77.3 \% / 1.1$ & $22.7 \% / 6.97$ \\
\hline $\bar{u}_{a x} / \bar{u}_{r}(-)$ & $100 \% / 0.33$ & $0 \% / 0$ \\
\hline T.I.r. $(-)$ & $100 \% / 0.37$ & $0 \% / 0$ \\
\hline
\end{tabular}

If the calculated $|t|$ value is less than the critical value of the t-distribution for $(m-2)$ degrees of freedom and significance level $\alpha$, the difference between $\beta_{\text {calc }}$ and $\beta_{\text {pred }}$ is statistically negligible (statisticians state: "the hypothesis cannot be rejected"). In our case, the independence of dimensionless velocities of the impeller Reynolds number was tested as the hypothesis, i.e. parameter $=B .(R e)^{0}=$ const., i.e. $\beta_{\text {pred }}=0$. The $\mathrm{t}-$ distribution coefficient $t_{(m-2), \alpha}$ for five impeller Reynolds numbers and significance level $\alpha=0.05$ is 3.1825 . The hypothesis testing was done for each point in the investigated area. The hypothesis test results are presented for investigated area in Table 2 by the percentage of points in which the above-formulated hypothesis parameter $=$ const. is satisfied and by the percentage of points in which the hypothesis parameter = const . can not be accepted. For illustration, the average values of calculated $|t|$ value are presented here also.
The dimensionless radial mean velocities were found in the range from 0.1 to 1.3 . The dimensionless axial mean velocities were found to be close to zero, in the range from 0.004 to 0.079 . These findings correspond to characteristics of the given zone, according to Fořt et al. [7]. This region contains predominantly radial stream from the impeller. Due to lower impeller clearance C/D the axis of the discharge flow is diverted from the impeller paddle axis. The dimensionless axial mean velocities are lower than the dimensionless values for radial mean velocity as expected for this region. The tested hypothesis can be accepted in the majority of profile points of the investigated area.

The dimensionless radial r.m.s. fluctuation velocities were found to be in the range from 0.184 to 0.536 . The tested hypothesis can be accepted in the majority of profile points, as is signalized by the low calculated $|t|$ values. The dimensionless axial r.m.s. fluctuation velocities were found to be in the range from 0.2 to 0.552 . The tested hypothesis can be accepted in the majority of profile points as is again signalized by the low calculated $|t|$ values.

On the basis of the results of this hypothesis test, we assume that all dimensionless velocities can be statistically taken as constant and independent of the impeller Reynolds number. The spatial distributions of dimensionless velocities for seven operational conditions were averaged and are presented in Figures $2-5$. For illustration, the axial profiles of velocity components are presented in Figures $6-9$ for selected radial positions $r^{*}$ $=0.4165,0.4485$ and 0.4837 . The axial profiles exhibit typical bell shape with the maximum, especially for $U_{r}{ }^{*}$ and $u_{a x}{ }^{*}$. The investigated area is shown in Fig. 1 by shadow form .The profiles obtained are in accordance with velocity profiles typical for region $\mathrm{O}$ as reported by Fořt et al. [8].

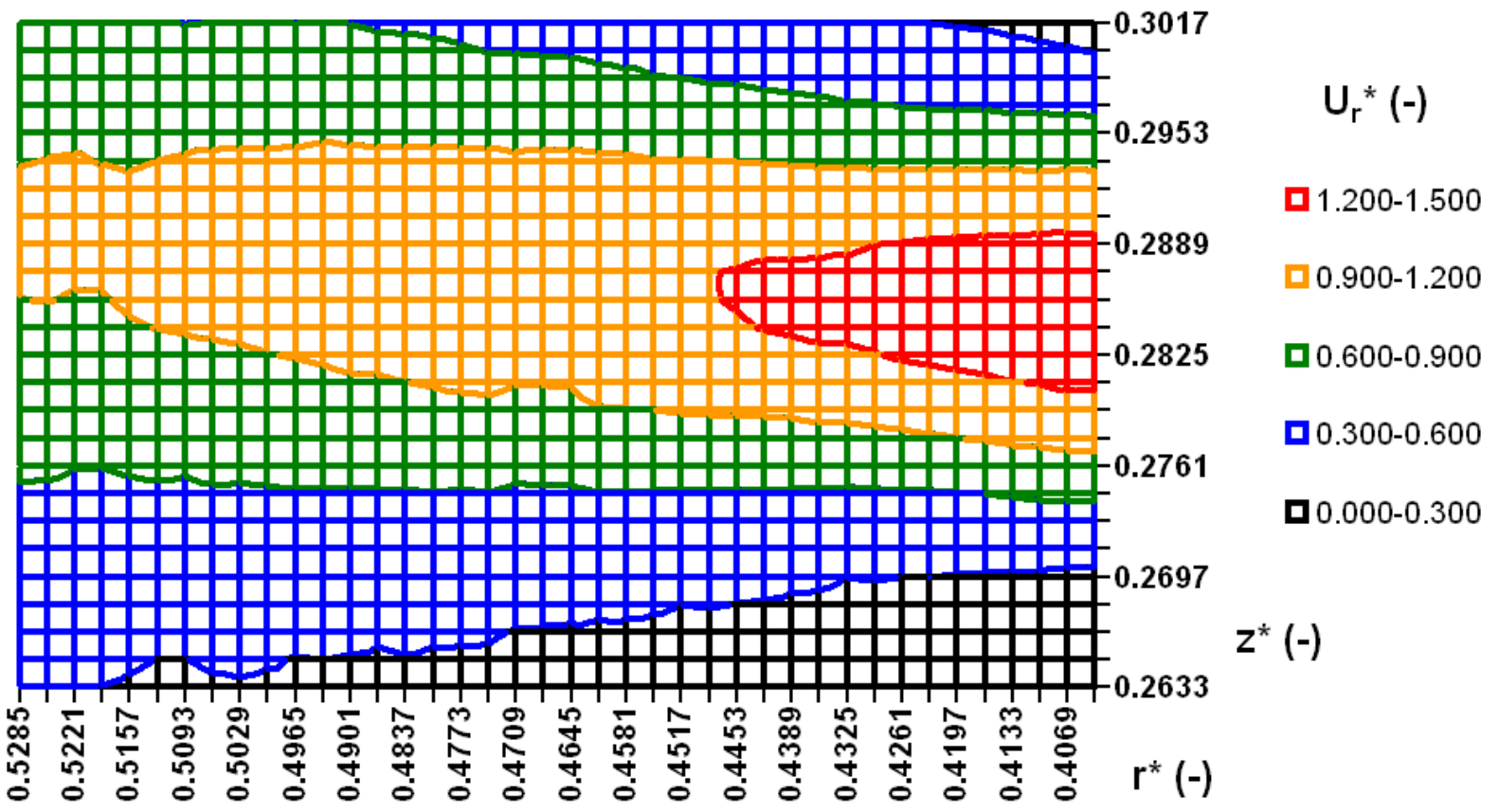

Fig. 2. Dimensionless radial mean velocity distribution $U_{r}{ }^{*}=\bar{U}_{r} /(N D)=\mathrm{f}\left(r^{*}, z^{*}\right)$ in the impeller discharge stream. 


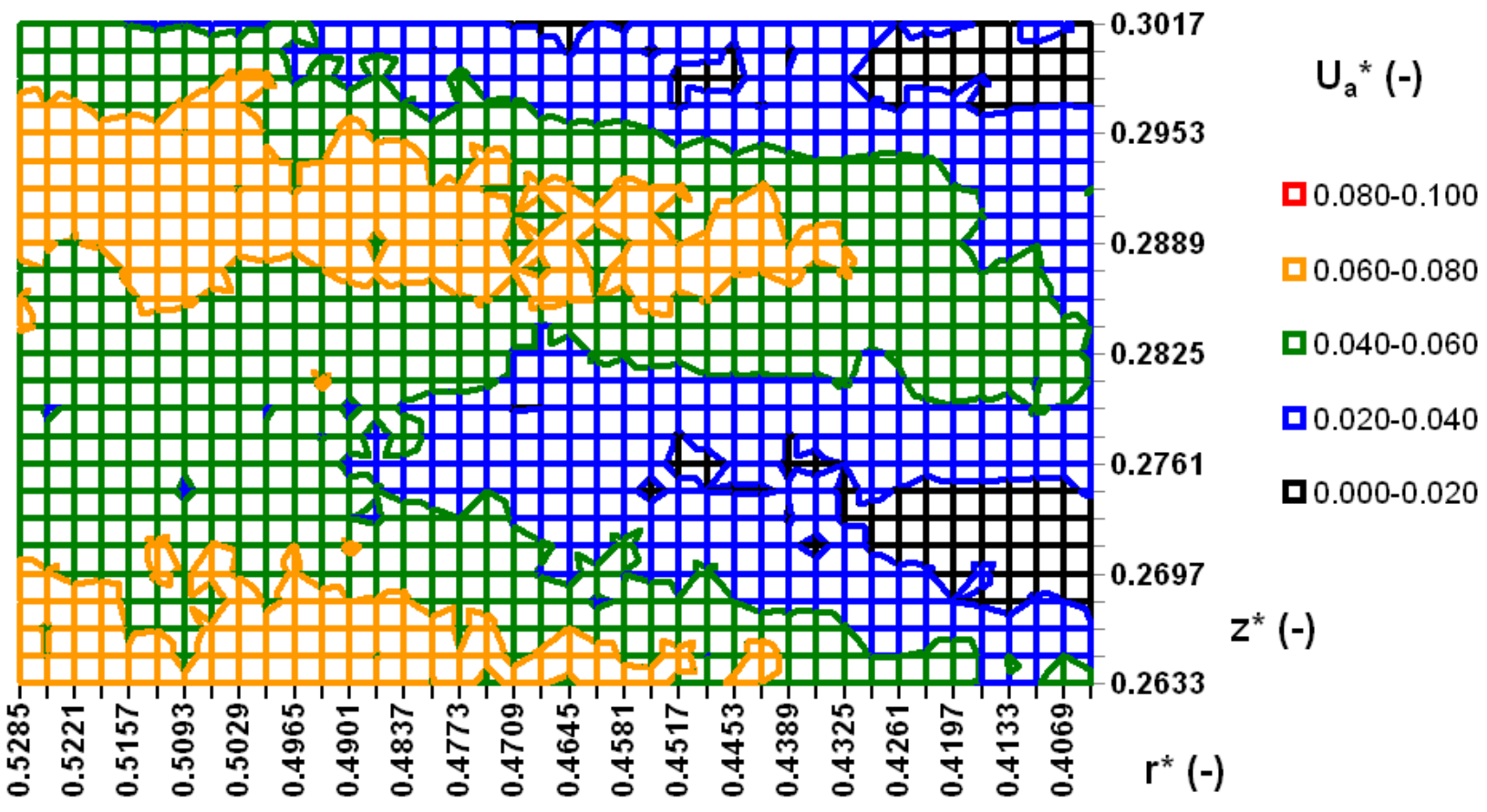

Fig. 3. Dimensionless axial mean velocity distribution $U_{a x}{ }^{*}=\bar{U}_{a x} /(N D)=\mathrm{f}\left(r^{*}, z^{*}\right)$ in the impeller discharge stream.

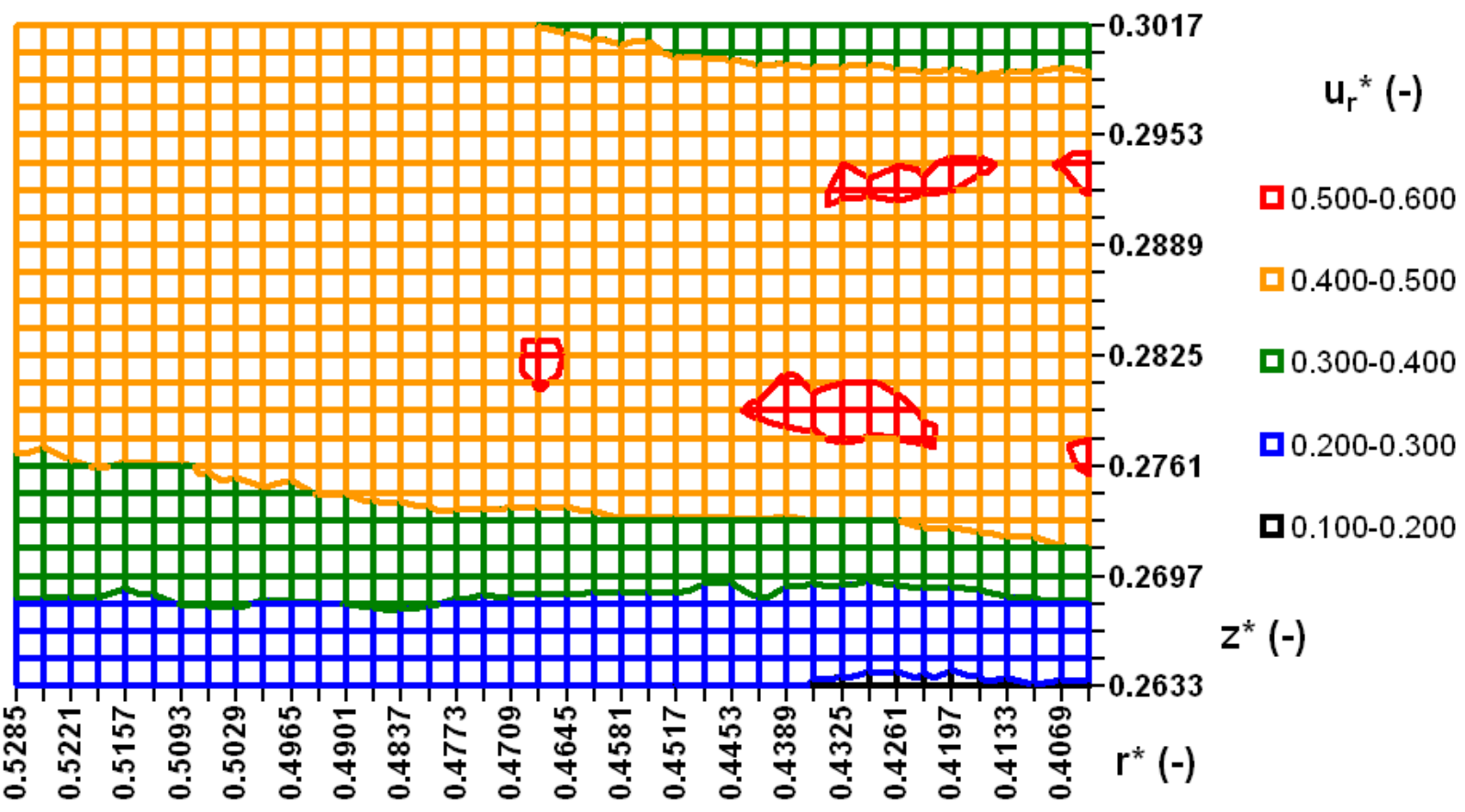

Fig. 4. Dimensionless radial fluctuation velocity distribution $u_{r}{ }^{*}=\bar{u}_{r} /(N D)=\mathrm{f}\left(r^{*}, z^{*}\right)$ in the impeller discharge stream. 


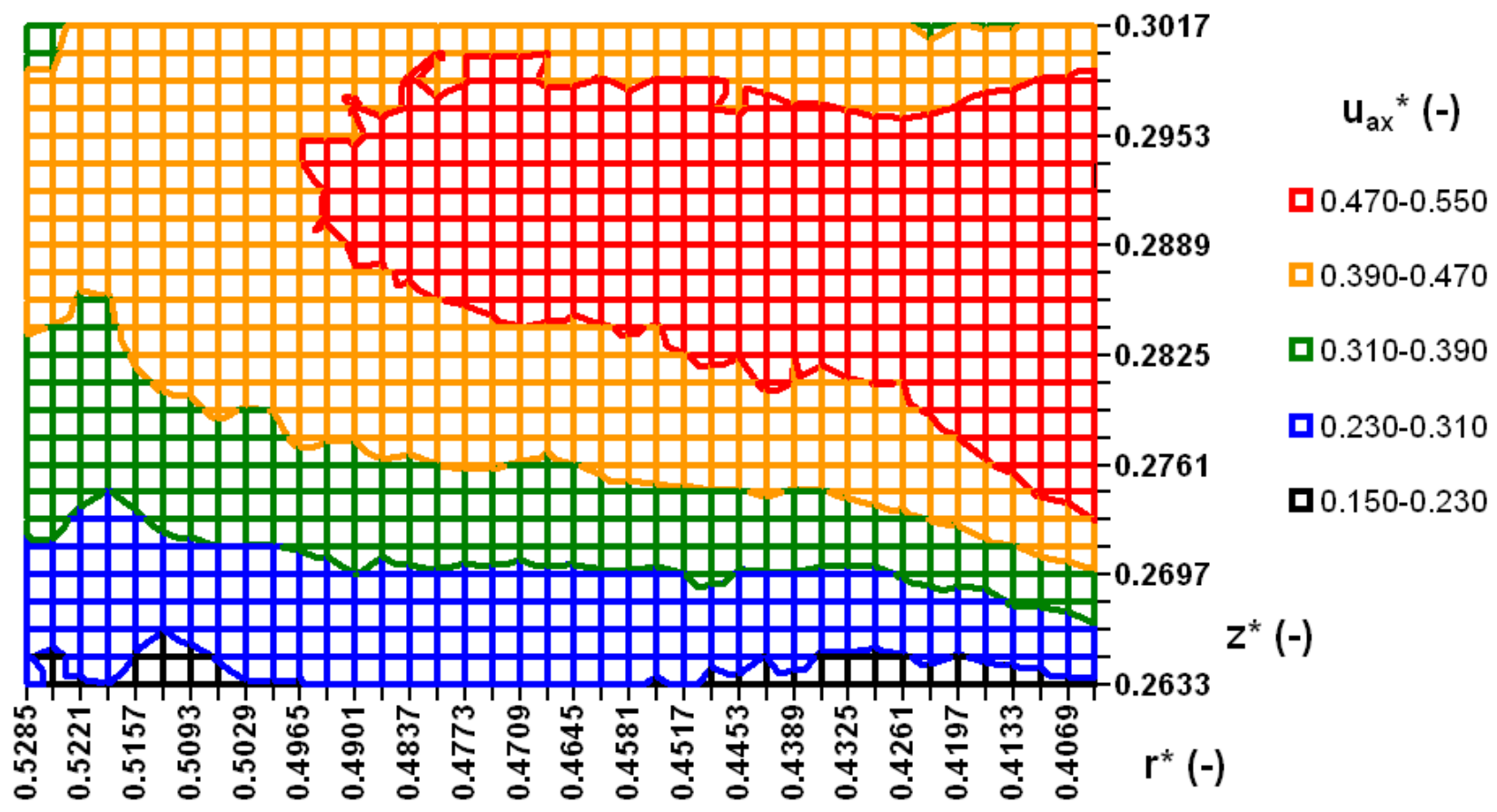

Fig. 5. Dimensionless axial fluctuation velocity distribution $u_{a x}{ }^{*}=\bar{u}_{a x} /(N D)=\mathrm{f}\left(r^{*}, z^{*}\right)$ in the impeller discharge stream.
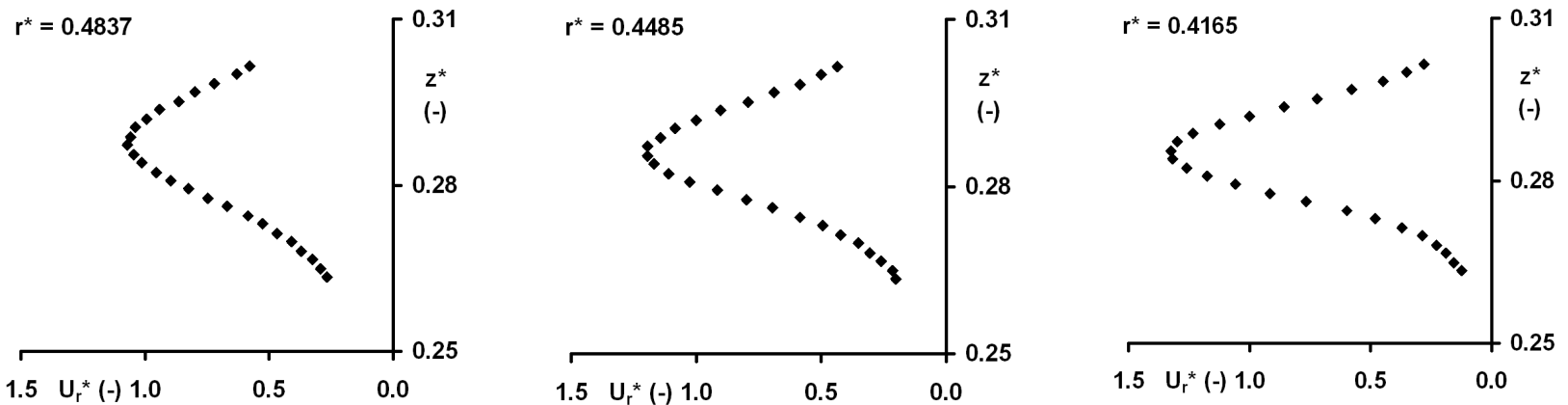

Fig. 6. Dimensionless radial mean velocity profiles $\bar{U}_{r} /(N D)=\mathrm{f}\left(z^{*}\right)$ in the impeller discharge stream.
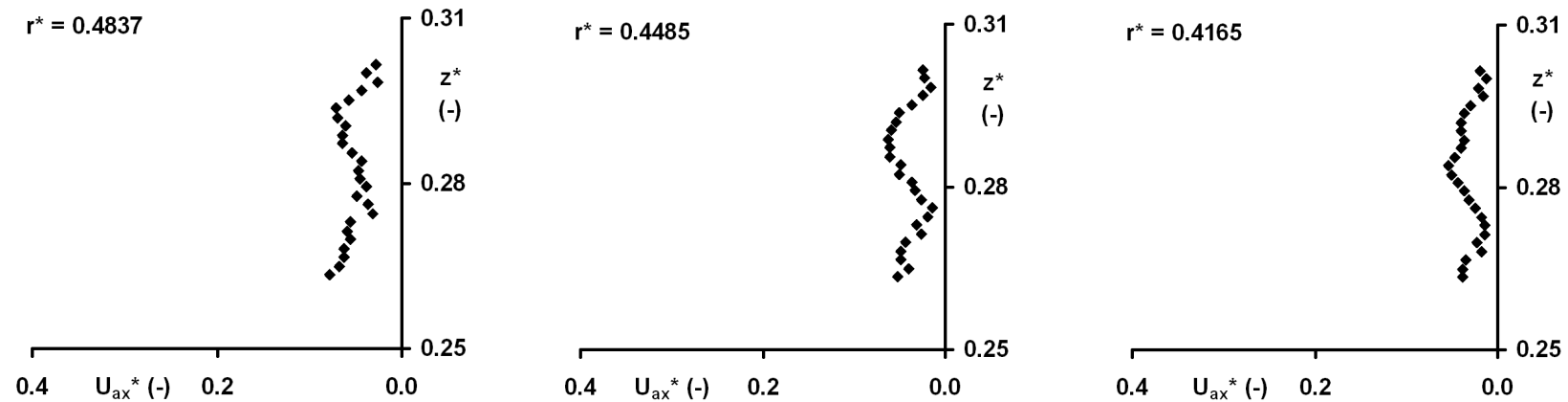

Fig. 7. Dimensionless axial mean velocity profiles $\bar{U}_{a x} /(N D)=\mathrm{f}\left(z^{*}\right)$ in the impeller discharge stream. 

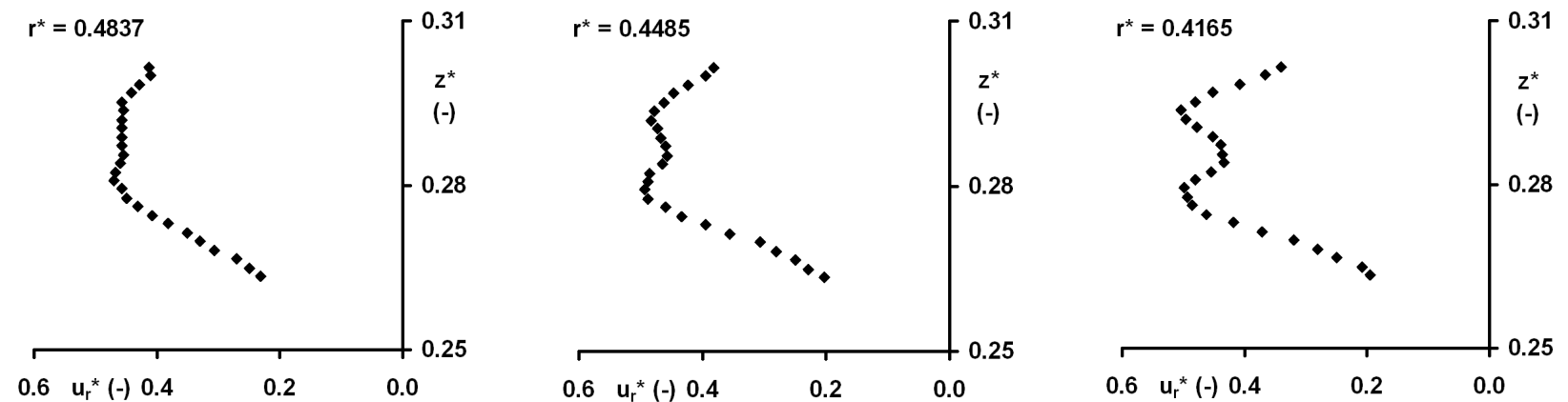

Fig. 8. Dimensionless radial fluctuation velocity profiles $\bar{u}_{r} /(N D)=\mathrm{f}\left(z^{*}\right)$ in the impeller discharge stream.
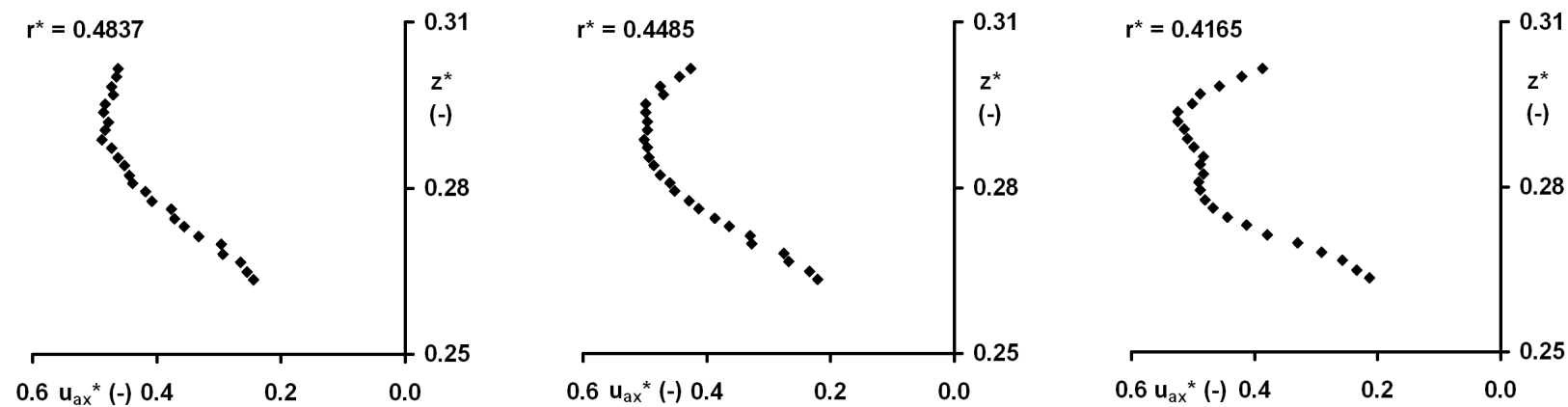

Fig. 9. Dimensionless axial fluctuation velocity profiles $\bar{u}_{a x} /(N D)=\mathrm{f}\left(z^{*}\right)$ in the impeller discharge stream.
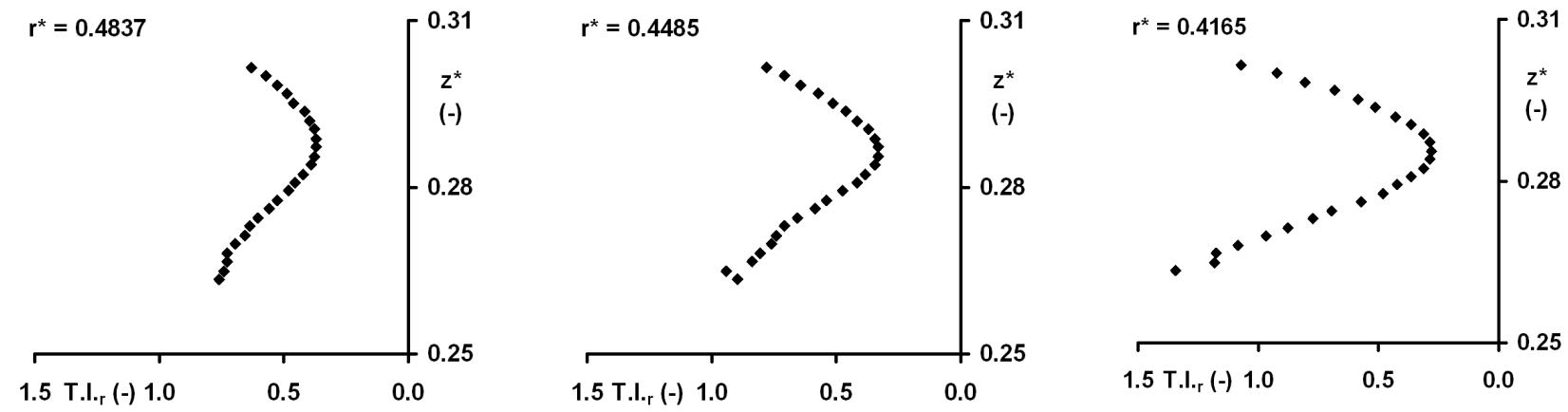

Fig. 10. Radial turbulence intensity profiles T.I.r $=\mathrm{f}\left(z^{*}\right)$ in the impeller discharge stream.

\section{Intensity of turbulence}

The radial turbulence intensity was calculated for each point in the investigated area as follows:

$$
T . I \cdot_{r}=\frac{\bar{u}_{r}}{\bar{U}_{r}}
$$

where $\bar{u}_{r}$ is radial r.m.s. fluctuation velocity, $\bar{U}_{r}$ is radial mean velocity. For dimensionless velocities independent of the impeller Reynolds number, the turbulence intensity should also be independent of this quantity. The independence of dimensionless velocities of the impeller Reynolds number was again tested by hypothesis testing. The t-distribution coefficient $t_{(m-2), \alpha}$ for five impeller Reynolds numbers and significance level $\alpha=0.05$ is 3.1825. Hypothesis testing was done for each point in the investigated area. The hypothesis test results are presented in Table 2, as well. 


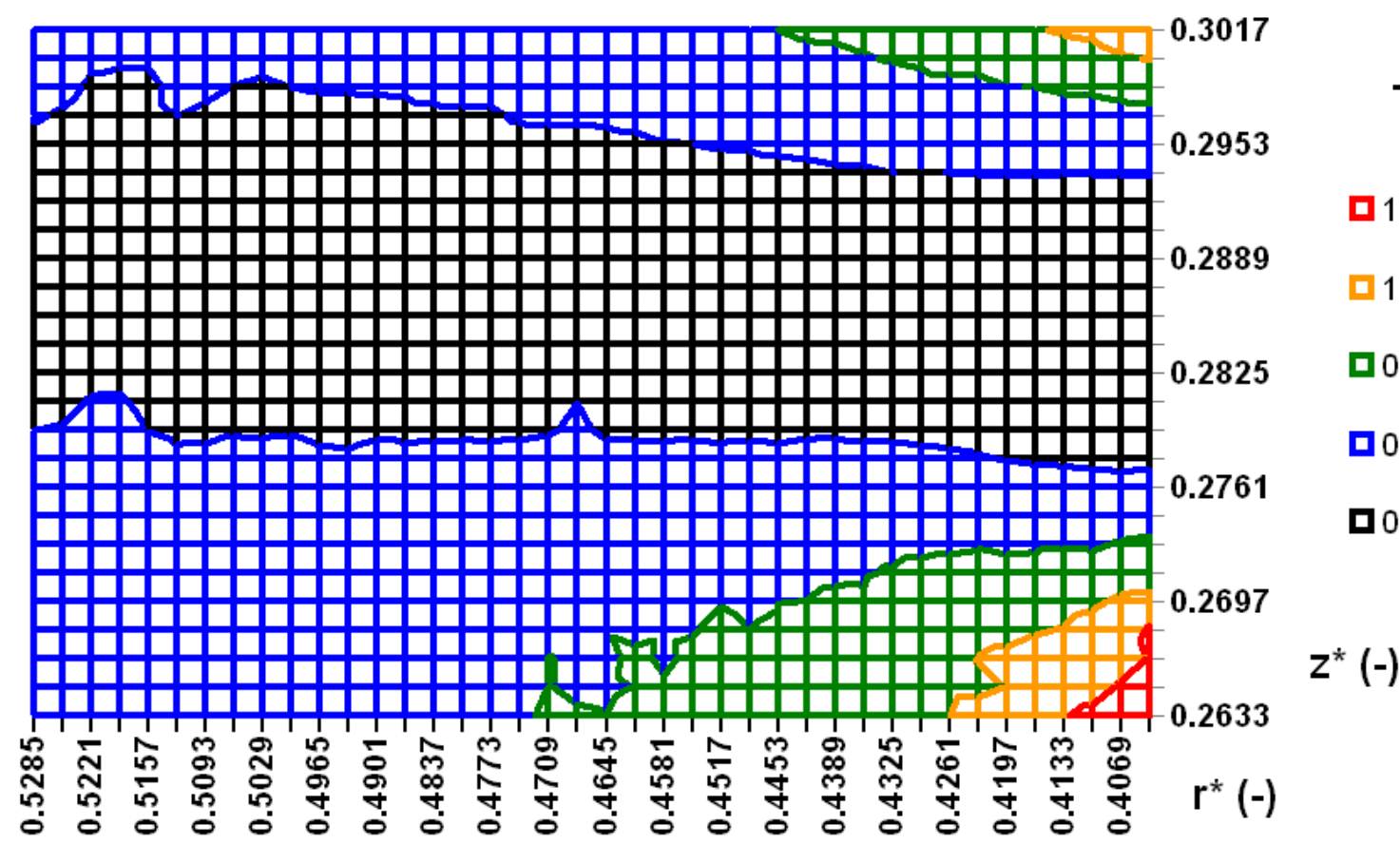

Fig. 11. Radial turbulence intensity distribution T.I.r $=\mathrm{f}\left(r^{*}, z^{*}\right)$ in the impeller discharge stream.

The tested hypothesis can be accepted in the majority of profile points. On the basis of these hypothesis test results, we assume that the radial turbulence intensity can be statistically taken as constant and independent of the impeller Reynolds number, as expected. As it was shown, the calculated values are in the majority of points in the range from 0.27 to 0.9 . These values correspond to high turbulence intensity. The radial profiles of radial turbulence intensity are presented in Figure 10 for selected radial positions $r^{*}=0.4165,0.4485$ and 0.4837 . The spatial distribution of quantity T.I. $r$ in the impeller discharge stream is shown in Figure 11.

\section{Conclusions}

The following results have been obtained in this study:

The hydrodynamics and flow field were measured in a vessel $400 \mathrm{~mm}$ in the inner diameter agitated by a tooth impeller using the 2-D Time Resolved Particle Image Velocimetry (2-D TR PIV). The velocity fields were detected in the impeller discharge stream for impeller rotation speeds from $300 \mathrm{rpm}$ to $700 \mathrm{rpm}$ and three liquids of different viscosities, corresponding to the impeller Reynolds number in the range $68000<\mathrm{Re}<$ 221000.

The dimensionless axial mean velocities were found to be close to zero. These findings correspond to the characteristics of the given zone according to Forrt et al. [5]. This region contains predominantly radial flow from the rotating impeller.

In accordance with the theory of mixing, the dimensionless mean and fluctuation velocities in measured directions were found to be constant and independent of the impeller Reynolds number. On the basis of the test results the spatial distributions of dimensionless velocities were calculated.

The radial turbulence intensity was calculated and was found to be in the majority of points in the range from 0.27 to 0.9 , which corresponds to high level of turbulence intensity. It was found that the radial turbulence intensity can be statistically taken as constant and independent of the impeller Reynolds number.

\section{Acknowldegment}

This research has been supported by Grant Agency of the Czech Republic project No. 16-20175S and by Ministry of Education, Youth and Sports of the Czech Republic project No. LO1201 (National Programme for Sustainability I) and RVO:67985874.

\section{Symbols}

B baffle width, $\mathrm{m}$

C impeller clearance, $m$

D impeller diameter, $m$

$\mathrm{H}$ liquid height, $\mathrm{m}$

$\mathrm{m}$ number of experimental points, -

$\mathrm{N}$ impeller rotational speed, $1 / \mathrm{s}$

$\mathrm{N}_{R}$ number of data in velocity data set, -

$r \quad$ radius (radial coordinate), $\mathrm{m}$

$r^{*} \quad$ dimensionless radius; $r^{*}=2 r / T$, -

Re impeller Reynolds number; $\mathrm{Re}=\mathrm{N} . \mathrm{D}^{2} / \mathrm{v},-$

$\mathrm{t}$ time, $\mathrm{s}$

$t_{i}$ observation time, $s$

$t_{R}$ record time, $s$

$t_{(m-2), a=0.05} t$-distribution for $(m-2)$ degrees of freedom and significance level $\alpha$, -

$\mathrm{T}$ vessel diameter, $\mathrm{m}$ 
T.I. turbulence intensity, -

$\mathrm{u}_{\mathrm{i}} \quad$ fluctuation velocity in $\mathrm{i}^{\text {th }}$ direction, $\mathrm{m} / \mathrm{s}$

$\bar{u}_{i}$ root mean squared fluctuation velocity in $\mathrm{i}^{\text {th }}$ direction, $\mathrm{m} / \mathrm{s}$

$\mathrm{U}_{\mathrm{i}} \quad$ instantaneous velocity in $\mathrm{i}^{\text {th }}$ direction, $\mathrm{m} / \mathrm{s}$

$\bar{U}_{i}$ mean velocity in $\mathrm{i}^{\text {th }}$ direction, $\mathrm{m} / \mathrm{s}$

$\mathrm{z} \quad$ actual height (axial coordinate), $\mathrm{m}$

$\mathrm{z}^{*} \quad$ dimensionless height; $\mathrm{z}^{*}=\mathrm{z} / \mathrm{T}$, -

\section{References}

1. B. Kysela, J. Konfršt, I. Fořt, M. Kotek, Z. Chára, Chem. and process Eng. 35, 137-147 (2014)

2. R. Šulc, V. Pešava, P. Ditl, Acta Polytechnica 54, 430-438 (2014)

3. R. Šulc, P. Ditl, I. Fořt, D. Jašíková, M. Kotek, V. Kopecký, B. Kysela, Local velocity scaling in T400 vessel agitated by Rushton turbine in a fully turbulent region. EPJ Web Conf., 143, Article No. 02120 (2017)

4. E.L. Paul, V.A. Atiemo-Obeng, S.M. Kresta (eds), Handbook of Industrial Mixing (Wiley \& Sons, USA, 2004)

5. P. Ditl, R. Šulc, Technical Transactions 113, 83-94 (2016)

6. V. Novák, F. Rieger, K. Vavro, Hydraulické pochody $v$ chemickém a potravinářském průmyslu (SNTL, Prague, 1989)

7. B. Kysela, J. Konfršt, Z. Chára, M. Kotek, EPJ Web of Conferences 67, 02065 (2014)

8. I. Fořt, A. Obeid, V. Březina, Coll. Czechoslov. Chem. Comm. 47, 226-239 (1982)

9. B.L. Bowerman, R.T.O'Connell, Applied statistics: improving business processes (Richard D. Irwin, USA, 1997) 